course would destroy and obliterate these delicate forms. There must be a steady set of wind, enough and not too much of it, and the air must be saturated with moisture in a certain state of molecular division. Some of these data might, perhaps, with the resources of a modern laboratory, be settled by experiment. If the experiment succeeded it would be an extremely pretty one.

F. POLLOCK C. C. Collier

Woodtown, Harabridge, South Devon, January 2

\section{Krukenberg's Chromatological Speculations}

$\mathrm{MY}$ attention has been lately called to a recent publication of Dr. C. F. W. Krukenberg, entitled "Grundziige einer Vergleichenden Physiologie der Farbstoffe und der Farben," in which some remarks and misstatements occur relative to my work, which in self-defence I feel I am not justified in letting pass without comment, ${ }^{1}$

(I) With regard to his observations on the colouring matter obtained by me from the integument of certain invertebrates and which I called "dermochrome," I do not see why I should have left it unpublished because three-quarters of a year before he had found that "lipochromes" were widely distributed in the animal kingdom. I found that lutein and hæmatoporphyrin occurred together in a peculiar combination, and said so. I suppose the offence lies in the name "Iutein." This word must now, according to Krukenberg, be got rid of, because he has chosen to call it "lipochrome." Perbaps, after all, "lutein" is more appropriate, as it does not mean fat pigment ; for this pigment occurs where there is no fat, e.g. it is not derived from fat in the Corpra lutea. Krukenberg bases his conclusions mainly on the reactions of the solid pigment with nitric and sulphuric acid and iodine, but I hope to have something to say on this point before long.

(2) Krukenberg maintains that the chlorophyll of cantharides is due to that in the intestines of these beetles. He committed himself to this theory at an early stage of his investigations, before he knew of Pocklington's observations; but after seeing the abstract of my paper read at the meeting of the British Association at Southport in 1883 , in which I called attention to Pocklington's work, he makes it appear that he knew all about it long ago, which is not fair. Now since Pocklington and I obtained chlorophyll from the elytra of these beetles, I do not think the above theory can be accepted, except it can be proved by Krukenberg that the intestine ramifies through the elytrce.

(3) Krukenberg says that $I$ "assume" that the chlorophyll spectrum seen by me in the integument of the larva of Pieris rape is due to chlorophyll in that situation, whereas it is really due to chlorophyll-holding masses in the intestine. I never did " assume" anything of the sort. I said distinctly at Southport that it was due to food chlorophyll in the intestine, as could easily be proved, for on emptying the intestine the chlorophyll band could no longer be seen. This must be a wilful misrepresentation, as he acquired the knowledge of Pocklington's work from the same abstract in which my explanation occurs.

(4) He further says that my knowledge of the literature of the subject must be great when I assume that he has confused " anthea green" and "diatom yellowe" whereas I said distinctly " it would appear, according to Geddes" (see Geddes' paper in NATURE, vol. xxv. p. 303) that he had confused them. I may, however, now observe that his supposition that the colouring matter of the yellow cells of Anthea is what he calls a " "hepatochromate" can easily be disproved ; all that is necessary is to add a little caustic potash or caustic soda to its alcoholic solution when the colouring matter becomes completely altered ; for this reason any deductions drawn from Krukenberg's "saponification method" in this case are of little value.

(5) Krukenberg says he had found "chlorophyll-like stuffs" in the livers of animals before I had done so. I am sure this statement is open to question, as his spectra are not accurate representations of what is seen in solutions of enterochlorophyll. In most cases only one or two bands are shown by him, and the other proofs brought forward by me are not given in the accompanying text. If his own test for a true chlorophyll be accepted, I can, and hope shortly to, show that animal chlorophyll is a true chlorophyll, and can be obtained in the crystallised state,

2 The papers in which my observations on the subjects referred to were published are - Proc. Roy. Soc., 1883 (No. 226); Proc Birminghan Philos. Soc., vol. iii., $188_{3}$; and Brit. Assoc. Reports, $188_{3}$. and the crystals are the same as those obtained by Dr. Hansen, an abstract of whose work will be found in this journal (vol. $\mathrm{xxx}$ p. 224).

(6) It is further suggested that the darkening of the bands in solutions of "echinochrome" (a pigment whose spectrum I have lately described) produced by adding sulphide of ammonium, is caused by precipitation of certain ingredients. This is not the case. The same appearance is produced by stannous chloride and other reducing agents. I have, however, lately succeeded in isolating this pigment, and can confirm my former results. I hope to publish shortly an account of the spectra of its solutions.

(7) Krukenberg makes it appear that I have said that the green gland of the crayfish contains hæmoglobin. I never said so. The statement was this: "In the green gland of one crayfish a band was detected which, I think, was due to reduced hamatin, but it was absent in the second specimen examined." Perhaps Krukenberg thinks that hæmoglobin and hæmatin are the same.

(8) I am made responsible for the statement that the eye of the house-fly contains hæmoglobin; I never said so, nor can I agree with Krukenberg that it gives no band. It gives a band at $\mathrm{D}$, and is not similar to the pigment of the eye of Cephalopods, which he assumes to be the case.

I leave the inferences to be deduced from the above statements to others ; but I must protest against Krukenberg's treatment of my work. It is at least satisfactory to know that my experience is not unique, as other English, German, French, and Italian workers receive an equally fair treatment by Dr. Krukenberg.

Wolverhampton, Dec. $23,1884 \quad$ C. A. MacMunN

\section{Our Future Clocks and Watches}

I wOULD suggest, as a modification of "R. B.'s" suggestion in NATURe (p. 8o), that the striking of the clocks on the twenty-four system might be varied at each quarter of the day, so as to indicate the time without so much striking. Thus, I (a.m.) to 6 might be indicated by the usual method; 7 could be indicated by two strokes, a pause, and one stroke ; 8 , by two strokes, a pause, and two strokes; and so on to 12 ; 13 , by three strokes, a pause, and one stroke ; and so on to 18 ; 19 , by four strokes, a pause, and one stroke; and so on to 24 , which being thus indicated by only ten strokes would require less effort to $\mathrm{c}$ unt, and make less noise than by the old system. Dials might be modified in the same way. Instead of twelve there would be only six divisions around the dial, and the quarter of the day could be indicated by a small wheel revolving behind a peephole, or by a third hand (which could be very short) revolving once a day over four divisions or quadrants, marked on the dial near the axis. People, however, would seldom or never need to look at this. Thus would be done away all the objec tions urged by Harmer. The hour-markings are only conven. tional signs any way, and it does not make any especial difference in what way the hours are indicated if people would only accustom themselves to the use of the twenty-four hour system in speaking and writing.

Ann Arbor, Michigan, December 20, I884

\section{MODE OF RECKONING TIME AMONGST VARIOUS PEOPLES}

THE recent Prime Meridian Conference at Washington has attracted attention to the methods employed at various periods, and amongst peoples in different stages of civilisation, to reckon time. Dr. Robert Schram, on October 24, read an interesting paper on this subject before the Geographical Society of Vienna, in which he dealt chiefly with the Chinese, Hindoos, and the Jews. The three units of measurement given by Nature herself are the rotation of the earth on its own axis, the revolution of the moon in its orbit, and that of the earth around the sun; these are wholly independent of each other, and neither is an aliquot part of the others. But from the earliest times efforts have been made to connect these units; there is the attempt to balance all three, which gives the luni-solar year, or those to connect the day with the course of the sun or of the moon, from which we get the solar or lunar year. In the earliest times the most complicated of these, the luni-solar year, in which it 
was sought to connect and cqualise all three units, was the onc most in use. This is comprehensible when we recollect that now we want to fix single days as far back or in the futurc, as we wish, and that therefore this form of year appears complicated to us; but in primitive times it was really the most simple form of all, for the sun and moon relieved man of the trouble of reckoning days, and in the months and seasons wrote large on the face of Nature herself the hours and minutes, if we regard the days as seconds. A glance at the heavens or at the surrounding vesretation must have told primitive man the most that he wanted to know of the passage of time, and have supplied the deficiencies of his calendar. How the luni-solar year came direct from Nature herself, and also how it was to be taken as an approximate method only, may be seen in the most ancient form of the Jewish year, which was so regulated that the feast of Passover should be celebrated when, during full moon the barley, which was required as an offering, was ripe, and it must be in the first month of the year, which was then Nisan. Twelve months then were counted from this; but if at the end there was no prospect that the barley would be ripe in fourteen days, a second month, Adar, was simply intercalated, and the new year began with the next new moon. But when an exact and rigid measurement of time is requircd, this form of year is simply perplexing. The three main types existing down to our own day of the luni-solar year are the Chinese, the Hindoo, and the Jewish years, and each of these is treated by Dr. Schram in turn.

With the Chinese, as in the case of almost every lunisolar year, every month begins with the new moon, and the first month is that in which the sun is in Pisces, the second that in the course of which it enters Aries, and so on. But if the sun in the course of a lunar month does not enter into a new zodiacal sign, it is regarded as an intercalary month, and receives the number of the previous month, with a maris of distinction. In this way months of 29 and 30 days succeed each other, but there is no fixed rule for this succession, nor for the place of the intercalary month of the year, nor for the succession of the intercalary years, and as the commencement of all the months and years have to be astronomically calculated, the whole year is somewhat uncertain and fluctuating, for a few minutes, or even seconds, may alter the beginning of a month by a day, and cause a difference in the intercalation of a month. It is difficult, too, to say according to what tables the astronomical data in the more ancient periods were calculated, so that it would be a matter of much uncertainty to transfer a date into another chronological system, if it were not for the circumstance that the Chinese from the most remote antiquity employed a cyclo of 60 days for reckoning the days, mucl as we employ the week, without regard to the movements of the sun or moon. The uncertainty of the year which prevents the fixing of a precise day two or three years hence has rendered the calendar an indispensable rade mecum. The compilation of the calendar has thus become a work of vast importance, which the State has taken on itself and committed to the care of an Imperial mathematical tribunal, presided over by a royal prince. When the work is periodically completed it is presented with grcat pomp to the members of the Imperial family and to the menbers of the Govermment. The ycars are counted among themselves in two ways, employed simultancously. The official year is the fourth, fifth, or as the case may be, of the reign of the Emperor, although even this is subject to alteration; while therc is also a scries of cycles of 60 years each, every individual year having a distinguishing name of it; own. These years are named on a system universal in Eastern $A$ sia, which is based on a combination of one name from ten Kan or "roots," with one from twelve Chi or "branches." This peculiar method of forming a cycle by the combination of two smaller cycles is found among the Japanese, Manchus, Mongols, and Thibetans, all of whom use the 6o-year cycle formed from the cycles of 10 and 12 years; also among the Aztecs a cycle of 52 years, formed from one of 4 and 13 years, is found, which led Humboldt to believe in an infusion of Asiatic ideas in Mexico. The years are more rarely given in a I2-year cycle, each having the name of some animal; this is also universal in Eastern Asia.

The Juni-solar year amongst the Hindoos was based on a sidereal solar year, the twelve months of which, though of uncqual lengths, were of fixed duration down to the minutest fraction of time. Thus the solar month Chaitra was 30 days, 20 hours, 21 minutes. 2 seconds, and 36 thirds. The day, however, had 60 , not 24 hours. The year bcgan with the new moon immediately preceding the commencement of the solar year. But if two lunar months began in the same solar month, the first was intercalated. In case no lunar month fell in the solar month, then that year would lose one of its ordinary months, but at some other part of its course it would have two intercalary months. Every month among the Hindoos has its proper name. The new moons with which they commence are calculated with great cxactness and according to inflexible rules, so that it is easier to go back than in the Chinese system. Still there is a difficulty, on account of the various systems employed at different early times. The fact, too, that the day is the thirtieth part of the lunar month, and thus shorter than the natural day, introduces an clement of doubt into calculations of this nature. The ycars are reckoned from o; the first year of the era is 0 , the second I, the third 2 , and so on, so that the number given to any one year is that of the preceding one. The 6o-year cycle is also employed, but it is not formed from the combination of two cycles; each year has its own namc. It is based on the course of Jupiter and contains five revolutions of that planet; but as the twelfth part of a revolution of Jupiter is only 361 days, I hour, 36 minutes, while the sidereal year contains 365 days, I 5 hours, 3 I minutes, 3 I seconds, 6/3rds, a new re-arrangemont is from time to time necessary, and a year of the cycle has to be periodically omitted. There are three separate rules for calculating when this is to be done. As eras are employed by the Hindoos for reckoning years, the cycle is of less importance. These eras are themselves divided into cycles of varying lengths. The current era is the Kali Yuga, or Iron Age ; 4985 years of it have already passed, so that it is little younger than the era of the creation; but according to Ifindoo notions it has still a vast course to run, and it is an age of which not only the beginning but also the end is precisely known. It is to last in all 432 ,000 ycars, and the earlier periods run as follows :-

$\begin{array}{lllr}\text { Kali Yuga, or Iron Age } & \ldots & \ldots & 432,000 \text { years } \\ \text { Dvapara Yuga } \ldots & \ldots & \ldots & 864,000 \quad,, \\ \text { Treta Yuga, or Silver Age } \ldots & \ldots & 1,296,000 \quad, \\ \text { Krita Yuga, or Golden Age } & \ldots & \mathbf{1}, 728,000 \quad,\end{array}$

These four form a so-called Maha Yuga, or Great Age, of $4,320,000$ years. Of these Maha Yugas there are $7 \mathbf{I}$, giving $306,720,000$ ycars, plus a twilight of $1,728,000$, give $308,448,000$ years, being the length of a patriarchate. There are fourteen of thesc patriarchates, or $4,318,272,000$ years, which, with a dawn of $\mathrm{I}, 728,000$ years, give 4,320,000,000 years, being a kalpa or xon of Hindoo chronology. But the ages extend beyond this, for an æeon, or kalpa, is only onc day of Brahma ; his night is of the same length, and 360 such days and nights form a year of his life, which lasts 100 of thesc years. The present age is the Kali Yuga of the 28 th Great Age of the 7 th patriarchate of the first acon of the second half of the life of Bralnna, who is therefore $155,521,972,848,985$ years old at present. But Brahma's whole life is only a wink of Siva's eye!

Another form of the luni-solar year is that of the Jews. 
In its later and more developed form this does not rest on observation or on fluctuating astronomical calculations, but on a comparatively simple cycle, based on a fixed month and year. Everything is settled beforehand: the intercalary month and year are inserted at stated pcriods. The system is the nineteen-year metonic cycle : nineteen solar years give 235 lunar months, in the course of which the $3,6,8,11,14,17$, and igth years are intercalary, a month being inserted between Adar and Nisan. The months are successively 29 and 30 days long, the times of each being settled. But simple as this appears, various circumstances have conspired to render Jewish chronology very complicated. Such are the inclusion of small fractions of time in calculating the new moon for the new year, and the frequent religious precepts dislocating the arrangement for the beginning of the year ; so that there are years of $353,354,355$, as well as those of 383,384 , and 385 days. The years were reckoned regularly from the creation of the world, which is placed on October 7 , 376 I B.C.

Having thus discussed the forms of the luni-solar year still in existence, Dr. Schram refers to those formerly in use by various nations. The Greeks also employed the cycle of nineteen lunar years, with seven intercalary months in every cycle, thus approximating to nineteen solar years. The months were of 29 and 30 days, and the years were reckoned by Olympiads of four years each. Subsequently Calippus brought the metonic cycle closer to solar periods by the omission of one day in cvery 76 years.

Among many peoples the modes of reckoning time do not deserve the name of a system. The Otaheitans used the changes of the moon, and the growth of the breadfruit; the Makha Indians on Cape Flattery the moon, and the seasons, of which latter they distinguished two, the cold and the warm; the Muysca Indians, according to Humboldt, had 37 lunar months in their cycle, and 20 of these cycles formed a larger one. Where there were no religious festivals connected with the new or the full moon, people gave up the luni-solar year altogether, and adopted the solar year only, confining themselves to bringing day and night into connection with it as far as possible, and paying no regard to the moon's course. It was soon found that the solar year was approximately 365 days in length, and this we find first in the year of the ancient Egyptians. They divided their solar year of 365 days into 12 months, each of 30 days, to which they added 5 supplementary days. The years were counted according to the reigns, and the Canon of Ptolemy is a chronological table giving the commencing years of the various kings. The same form of year is found amongst the Persians, with the difference that the supplementary days were added to the 8 th and not to the I2th month. Their months had names, not numbers, and their years were reckoned from the accession of Jezdegird, an era from which the Persians, especially in some parts of India, still count their years. It is remarkable that so inexact a year, originating so long ago, should have existed through centuries down to our own day, although its incorrectness was early recognised. The Egyptians, for whom the time of the rising of the Nile, at the ascent of Sirius, was of great importance, noticed soon that the occurrence came later and later in their year, and that if the Dog-star rose one year on New Xear's Day, four years later it was the second day, eight years the third, and so on. On this they based the Sothis, or Dogr-star period of I46I Egyptian years, in the course of which Sirius rose successively on every day of the year. Then came the knowledge of the year of $365 \frac{1}{4}$ days, which is tolerably exact, and of this there are several forms of years. In Egypt the change to the more exact reckoning was accomplished in a simple way. The months of 30 days and their names were retained, but to three of them in succession 5 days were added, and every fourth year the supplementary day gave 6 days to I month. This form of year is called the Alexantrian, and it is used at present by the Copts in connection with the Diocletian era. This year of $365 \frac{1}{4}$ days was carried to Rome by Caesar, where the method of counting time was in disorder ; and henceforth in Rome the year was of this length, the months consisting of different numbers of days, in place of the Alcxandrian supplementary days. This system forms the foundation of our calendar, and is the well-known Julian reform. A peculiar, form of the year of $365 \frac{1}{4}$ days was that of the ancient Mexicans. Their solar year consisted of 18 months of 20 days each; at the end of the year 5 supplementary days were added and at the end of 52 years, 13 more days. The old Icelandic year also was very peculiar. The unit there was the week of 7 days, and in order to make the year an exact number of weeks, there were I 2 months of 30 days each, with only 4 supplementary days at the end. Then at the end of 6 or 7 years another week was added, so that the ordinary year consisted of exactly 52 weeks, while the leap year had just 53 . The year of $365 \frac{1}{4}$ days was, however, a little too long, and in about 128 years there was an error of $I$ day. In the Julian as well as in the Alexandrian system an improvement was found. The former was re formed by Pope Gregory XIII., not so much in the form of the year, as in the method of intercalating. In every year divisible by 100 the intercalary day was to be omitted; but in those divisible by 400 it was to be introduced. Shah Shelal Eddin reformed the Alexandrian system by an ordinance that when the intercalation had taken place every fourth year for 7 or 8 times, the next time it should not take place till 5 years had elapsed. In other words every seventh or eighth leap year was to be the fifth, not the fourth year: Thus there would be 7 leap years in 29 , or 8 in 33 years. The last attempt to reform the Alexandrian system was made during the French Revolution, partly with the object of introducing the decimal system into time reckoning, partly also to get rid of all reference to Christianity or any other form of confession. The year which was then introduced was based on the Alexandrian year, but the intercalation was different. The months, consisting of 30 days each, reccived the names of Vendémiaire, Brumaire, Frimaire, Nivose, \&c., and were divided into 3 decades of to days each, which took to some extent the places of the weeks. The intercalation was not cyclical, but based on exact astronomical calculations, and it was decreed that the first Vendémiaire should commence with the day on which, according to exact Paris time, the sun entered the autumnal equinox. It is easy to see that this method of intercalating could not exist long without reform, even if there were no independent objections to it, for it has all the defects of the Chinese year. The years were counted from the proclamation of the Republic.

The lunar year is the last portion of his subject treated by Dr. Schram. All that can be said about it occupies but a small space. Here a balancing of the days and of the course of the moon alone is required, the movements of the sun, and the change of the seasons being wholly disregarded. The Turks and Arabs use this year, and indeed it is common all over the Mohammedan world. The ycar has iz lunar months; but the Turkish year can hardly be called a year in our sense of the term, with its regular succession and return of the seasons. In the course of 33 years the beginning of this year ranges over the whole of the seasons. If a Turkish festival comes one year in the depth of winter, I6 years later it will be at midsummer. The 12 months have 30 and 29 days $;$ in the leap year the last month has 30 instead of 29 days. In a cycle of 30 years, the leap years are the 2 nd, 5 th, Ioth, I 3 th, I 5 th, I 8 th, 2 Ist, 24 th, 26 th, and 29 th years. The years are counted from the flight of Mohammed from Mecca to Medina. 